\title{
OPEN Observed three dimensional distributions of enhanced turbulence near the Luzon Strait
}

\author{
Jianfeng Wang ${ }^{1,2,3}$, FeiYu ${ }^{1,2,3,4 凶}$, Feng Nan ${ }^{1,2,3}$, Qiang $\operatorname{Ren}^{1,2}$, Zifei Chen ${ }^{1,4}$ \& \\ Tongtong Zheng ${ }^{1,4}$
}

Ocean turbulence can impact the transfer of heat, nutrients, momentum and sea level rise, which are crucially important to climate systems. The Luzon Strait, one of the mixing hotspots, is important for water exchange between the northeastern South China Sea and West Pacific. Here, for the first time, we carry out full-depth direct microstructure measurements surrounding the Luzon Strait to clarify the three-dimensional distributions of turbulence. We demonstrate that the turbulent kinetic energy dissipation rates in the upper and middle layers of the northeastern South China Sea are on the same order of magnitude as those in the West Pacific. The dissipation rates are only bottom enhanced near the rough topography of the South China Sea slope and Luzon Strait which is one order of magnitude larger than those at smooth area. The relevant bottom diapycnal diffusivity in the South China Sea is elevated in the West Pacific by a factor of three, instead of by two orders of magnitude as overestimated by indirect parameterization. These results may appear surprising in light of previous studies but are in fact consistent with predictions from internal wave-topography interaction theory.

The distribution and magnitude of ocean mixing impact the transfer of heat, nutrients, momentum, and sea level rise, which are crucially important to oceanic dynamics ${ }^{1,2}$. Recent work has shown that the distribution and magnitude of mixing may play critical roles in a variety of climate systems ${ }^{3,4}$. Open-ocean thermocline mixing is an order of magnitude smaller than the value required $\left(10^{-4} \mathrm{~m}^{2} \mathrm{~s}^{-1}\right)$ to maintain global abyssal stratification ${ }^{5}$. Enhanced mixing with diffusivities higher than $10^{-4} \mathrm{~m}^{2} \mathrm{~s}^{-1}$ has been observed over rough topographies ${ }^{6-8}$.

The Luzon Strait (LS) is the only deep channel connecting the northeastern South China Sea (NSCS) and the West Pacific (WP), with peak-to-peak baroclinic velocities and vertical displacements often exceeding $2 \mathrm{~ms}^{-1}$ and $300 \mathrm{~m}$, respectively ${ }^{9}$. The topography surrounding the LS covers a wide range of bathymetric features, including two parallel ridges, deep basins, and steep continental slopes. Interacting with rough topography, energy converts from barotropic tides to internal tides ${ }^{10}$. Observations have revealed that the turbulent kinetic energy dissipation rate $(\varepsilon)$ throughout the LS are some of the strongest ever measured ${ }^{11}$. Turbulent mixing in the LS drives water exchange between the NSCS and the WP, which is important for NSCS circulation and heat and salt budgets ${ }^{12}$.

Studies of temporal and spatial variations in turbulent mixing in the South China Sea (SCS) and LS have been carried out using microstructure observations and fine-scale parameterization. Limited by strong currents near the LS, previous microstructure measurements have mostly focused on the upper layer above $500 \mathrm{~m}^{13-17}$. Finescale parameterization has been used as a supplement for observations, and on this basis, it has been proposed that mixing in the NSCS is enhanced $\left(10^{-3} \mathrm{~m}^{2} \mathrm{~s}^{-1}\right)$ by two orders of magnitude over that in the WP, with limited microstructure observation in the upper layer ${ }^{18,19}$. Elevated turbulent mixing $\left(10^{-2} \mathrm{~m}^{2} \mathrm{~s}^{-1}\right)$ has been reported in the whole water column of the $\mathrm{LS}^{19}$. Some studies have suggested that enhanced mixing in the SCS and LS is mainly attributed to baroclinic tidal dissipation ${ }^{11,20}$.

Previous studies have greatly improved our knowledge of turbulent mixing in the SCS and LS. However, knowledge of mixing in deep layers of the SCS is mostly from fine-scale parameterization, which may introduce uncertainty in understanding turbulence variability in the deep ocean. Many existing ocean circulation models cannot explicitly resolve diapycnal mixing. Studies based on models have shown that a wide range of ocean dynamic processes are sensitive to the intensity and distribution of diapycnal mixing ${ }^{21,22}$. The results from numerical simulations based on simple parameterizations of diapycnal diffusivity should be treated with caution. Furthermore, numerical predictions of energy budgets cannot be tested without direct microstructure

${ }^{1}$ CAS Key Laboratory of Ocean Circulation and Waves, Institute of Oceanology, Chinese Academy of Sciences, Qingdao 266071, China. ${ }^{2}$ Center for Ocean Mega-Science, Chinese Academy of Sciences, Qingdao 266071, China. ${ }^{3}$ Pilot National Laboratory for Marine Science and Technology (Qingdao), Qingdao 266237, China. ${ }^{4}$ University of Chinese Academy of Sciences, Beijing 100049, China. ${ }^{\square}$ email: yuf@qdio.ac.cn 


\begin{tabular}{|l|l|l|l|l|}
\hline Station & Longitude $\left({ }^{\circ} \mathrm{E}\right)$ & Latitude $\left({ }^{\circ} \mathrm{E}\right)$ & Time to reach the bottom & Depth $(\mathbf{m})$ \\
\hline C36 & 118.2463 & 22.0033 & $05 / 29 / 201806: 54: 30$ & 1550 \\
\hline C35 & 119.0567 & 18.6094 & $06 / 04 / 201813: 22: 33$ & 4025 \\
\hline C34 & 119.0452 & 19.2598 & $06 / 05 / 201807: 46: 20$ & 3661 \\
\hline C33 & 119.0483 & 19.9315 & $06 / 05 / 201815: 16: 39$ & 3004 \\
\hline C32 & 119.0544 & 20.6133 & $06 / 05 / 201822: 59: 54$ & 2767 \\
\hline C31 & 119.0509 & 21.1259 & $06 / 06 / 201807: 15: 02$ & 2693 \\
\hline C20 & 119.8026 & 21.8971 & $06 / 06 / 201817: 01: 44$ & 2199 \\
\hline C22 & 119.7927 & 21.197 & $06 / 07 / 201805: 47: 04$ & 3390 \\
\hline C24 & 119.7984 & 20.3974 & $06 / 07 / 201814: 23: 01$ & 3256 \\
\hline C26 & 119.8006 & 19.5973 & $06 / 08 / 201809: 17: 48$ & 3895 \\
\hline C18 & 120.5195 & 19.8709 & $06 / 09 / 201820: 36: 31$ & 3695 \\
\hline C16 & 120.5029 & 20.4092 & $06 / 10 / 201807: 17: 31$ & 2550 \\
\hline C14 & 120.4976 & 20.9786 & $06 / 10 / 201817: 16: 29$ & 1725 \\
\hline C10 & 122.662 & 21.6777 & $06 / 12 / 201819: 49: 53$ & 4799 \\
\hline C12 & 123.995 & 21.6597 & $06 / 23 / 201814: 53: 34$ & 5550 \\
\hline C11 & 123.3321 & 21.6613 & $06 / 23 / 201822: 45: 12$ & 5450 \\
\hline C05 & 122.0889 & 22.3509 & $06 / 24 / 201811: 26: 22$ & 4600 \\
\hline C29 & 119.0337 & 22.1479 & $12 / 10 / 201709: 27: 48$ & 1082 \\
\hline C01 & 122.0733 & 23.0092 & $07 / 30 / 201907: 27: 24$ & 4866 \\
\hline C09 & 122.0800 & 21.6693 & $08 / 03 / 201918: 26: 35$ & 4702 \\
\hline C13 & 120.5228 & 21.3014 & $07 / 27 / 201913: 49: 37$ & 1267 \\
\hline C20 & 119.8039 & 21.9545 & $07 / 27 / 201901: 56: 43$ & 2223 \\
\hline C28 & 119.8047 & 18.7805 & $07 / 24 / 201908: 16: 53$ & 3786 \\
\hline C29 & 119.0616 & 22.1692 & $07 / 21 / 201917: 34: 09$ & 975 \\
\hline C37 & 118.2546 & 21.2557 & $08 / 04 / 201918: 00: 31$ & 2115 \\
\hline C39 & 118.2439 & 19.788 & $08 / 05 / 201912: 42: 58$ & 2664 \\
\hline & & & & \\
\hline
\end{tabular}

Table 1. VMP-X stations and deployed time.

measurements from the LS. Confusion has persisted regarding the spatial distribution of turbulent mixing in the SCS and LS owing to the lack of in situ full-depth data because of the extremely challenging operating conditions ${ }^{9}$.

From our direct observation, direct results do not support the orders of magnitude of enhanced mixing in the SCS obtained from indirect measurements ${ }^{18,19}$. Our observations show that the dissipation rate in the NSCS is one order of magnitude higher than that in the WP and that the related diapycnal diffusivity in the NSCS is of the same order of magnitude as that in the WP. Enhanced dissipation is strongly related to the roughness and slope of topography.

\section{Results}

Field observations. The objective of this paper is to clarify the full-depth three-dimensional distribution of small-scale turbulence based on direct measurements near the LS. Field observations were performed at 24 stations from May 29 to June 24, 2018, and from July 21 to August 5, 2019, in the NSCS and WP (Table 1), which covered a wide range of bathymetric and oceanographic conditions (Fig. 1). Measurements were taken using an expendable vertical microstructure profiler (VMP-X, Rockland Scientific Inc.), a conductivity-temperature-depth (CTD) profiler (911-plus, Sea-Bird Electronics), and two 300-kHz lowered acoustic Doppler current profilers (LADCPs) (Teledyne RD Instruments, one upward-looking and the other downward-looking). The VMP-X was equipped with 2 standard shear probes and 1 temperature sensor at the expendable ballast to fall at $\sim 0.8 \mathrm{~ms}^{-1}$. Confined by rope length, traditional tethered microstructure profilers cannot reach deep depths under the influence of strong currents near the LS. The VMP-X works without a rope and releases the ballast when it reaches either a target depth $(6000 \mathrm{~m})$ or the seafloor ${ }^{23}$, which allows full-depth measurements at all stations. Without interference from the rope of the VMP-X, the CTD and LADCP were deployed together with the VMP-X, allowing quasi-synchronous sampling of CTD and microstructure data. Most CTD measurements can reach $50 \mathrm{~m}$ above the bottom, and the potential density $\left(\sigma_{\theta}\right)$ was calculated based on CTD data.

A $75-\mathrm{kHz}$ upward-looking moored acoustic Doppler current profiler (ADCP) was deployed at $22.10^{\circ} \mathrm{N}$, $119.28^{\circ} \mathrm{E}$, which is close to station C29, at a depth of $1135 \mathrm{~m}$ from July 25, 2017, to January 26, 2018. Velocity profiles were collected at an interval of $20 \mathrm{~min}$ using $8-\mathrm{m}$ vertical bins. The first effective bin was located $16.7 \mathrm{~m}$ above the bottom. The ADCP measured velocity profiles within $500 \mathrm{~m}$ above the bottom. Gregg-Henyey-Polzin (GHP) scaling based on internal wave-wave interaction theory ${ }^{25}$ was applied to ADCP data to estimate the time series of the dissipation rate and to evaluate the variation in the dissipation rate. The buoyancy frequencies used in the GHP method are from global physical analysis and a coupled forecasting product ${ }^{24}$ modeled by the Met Office Coupled Atmosphere-Land-Ocean-Ice data assimilation system (CPLDA). 

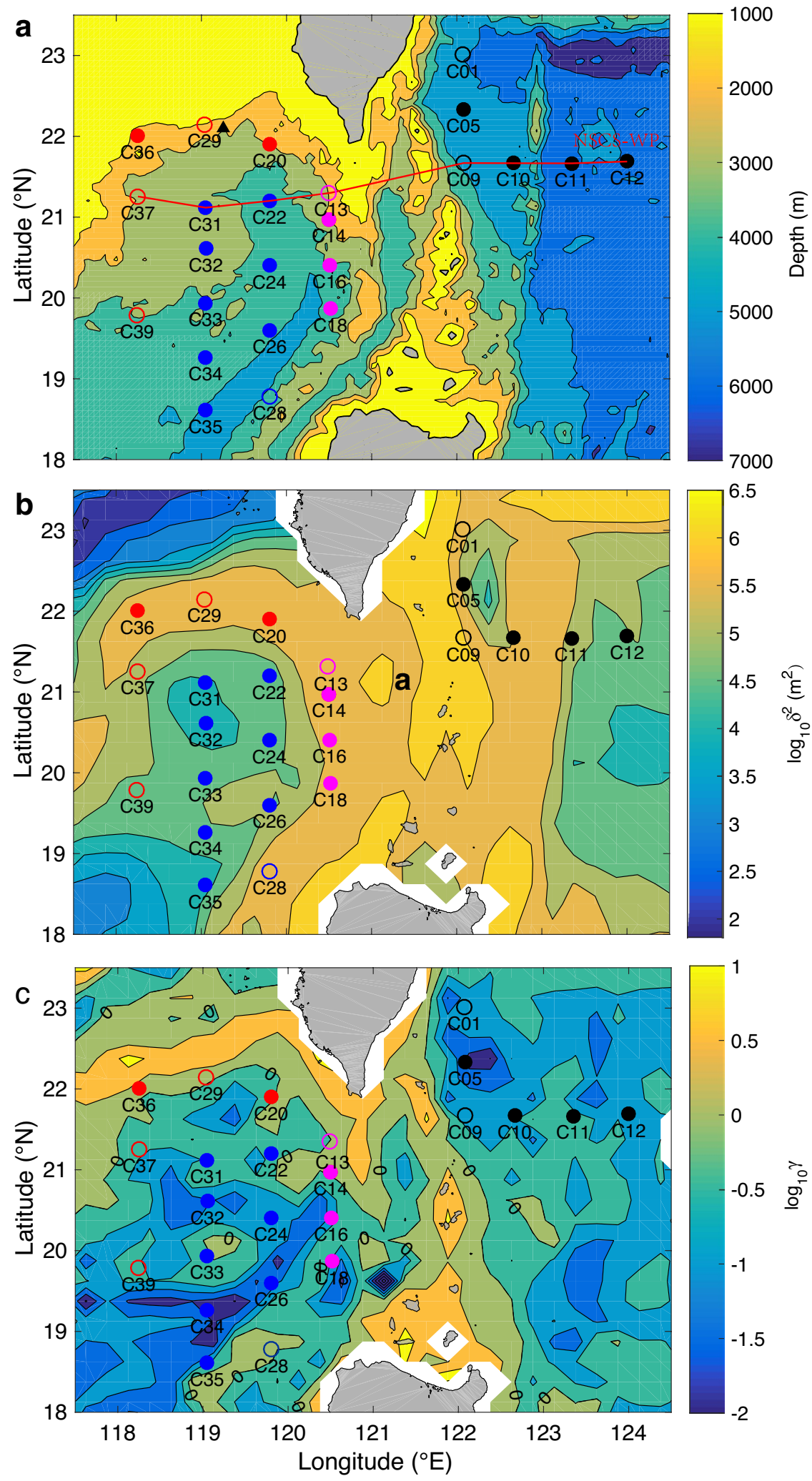

Figure 1. Map of the cruise area in the northeastern South China Sea (NSCS) and West Pacific (WP) showing microstructure measurement stations at the NSCS slope (red dots and circles), NSCS basin (blue dots and circles), and Luzon Strait (LS, magenta dots and circles) with the background topography (a), roughness $\left(\delta^{2}, \mathbf{b}\right)$ and slope criticality $(\gamma)$ for semidiurnal tides (c). The red line (in panel a) indicates the cross-section in Fig. 2. Dots and circles represent microstructure profiles taken in 2018 and 2019, respectively. The black triangle near C29 is the station where the moored ADCP was deployed. Figures were plotted using MATLAB R2016b (http:// www.mathworks.com/). 
a

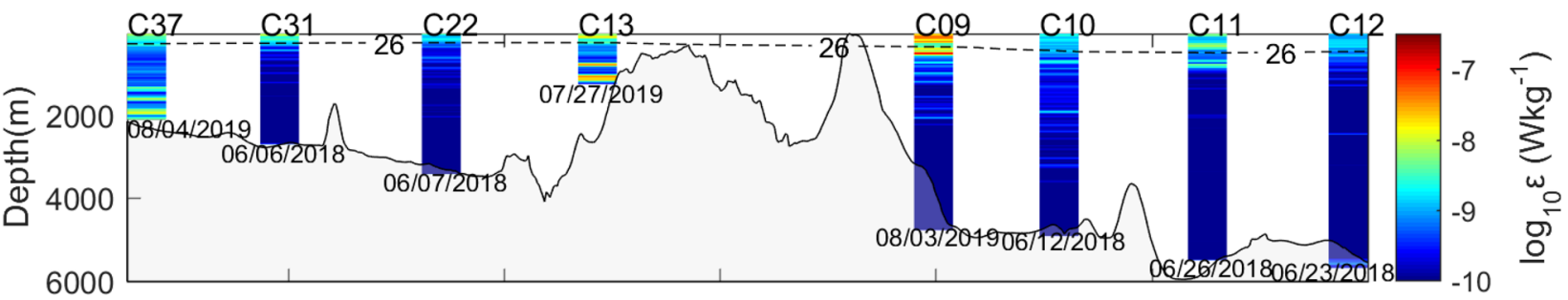

b

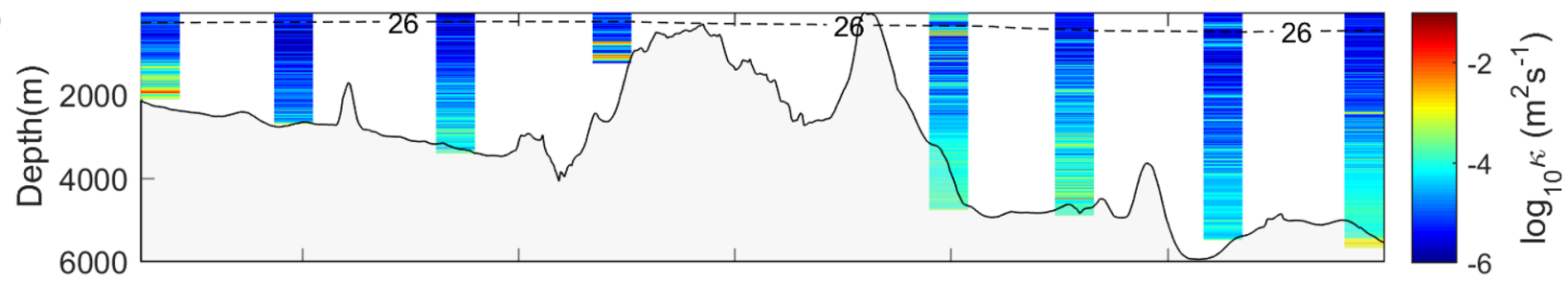

C

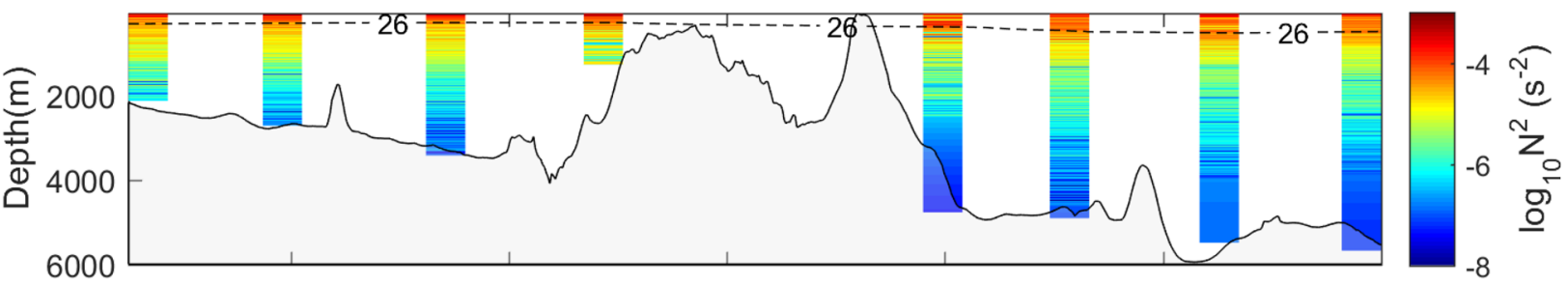

d

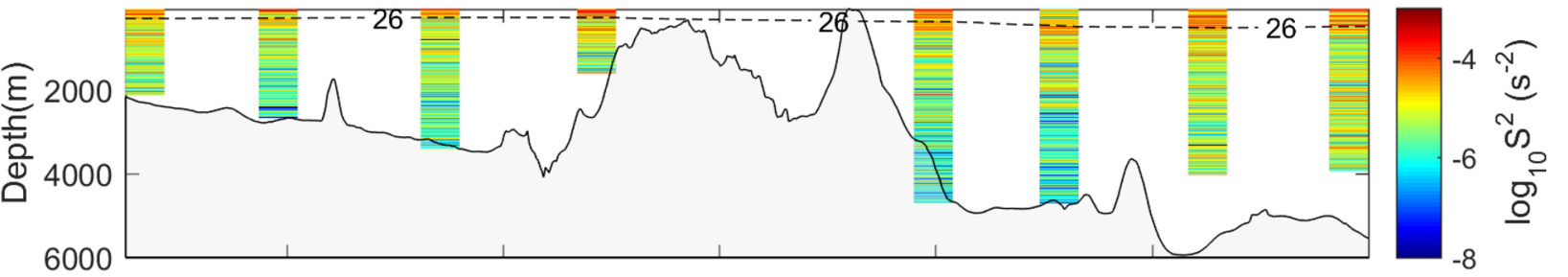

e

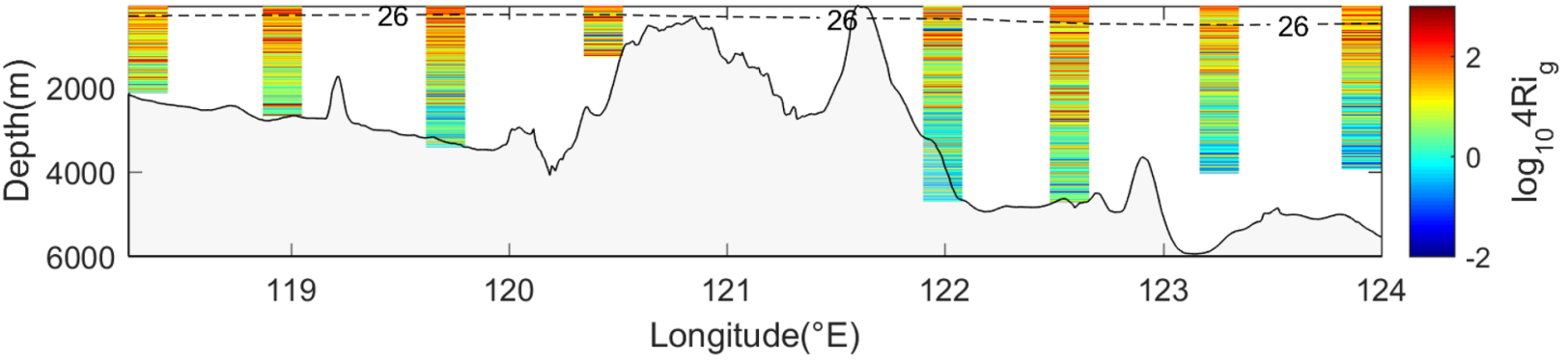

Figure 2. (a) Dissipation rate $(\varepsilon)$, (b) diapycnal diffusivity $(\kappa)$, (c) squared buoyancy frequency $\left(N^{2}\right),(\mathbf{d})$ shear squared $\left(S^{2}\right)$ and 4 times the gradient Richardson number (e) for the NSCS-WP cross-section in Fig. 1. The gray shading indicates bathymetry. In $(\mathbf{a}-\mathbf{e})$, the boundaries of the thermocline upper layer are taken as the $26-\sigma_{\theta}$ isopycnal (dashed line), and the bin size is $10 \mathrm{~m}$.

Vertical distributions of turbulence along the NSCS-WP cross-section. Cross-section along $21^{\circ}$ $\mathrm{N}$ is widely used to compare turbulent mixing of the NSCS and WP $\mathrm{P}^{9,18}$ since the internal tide energy flux is strongest within a beam that emanates from the LS between $20^{\circ} \mathrm{N}$ and $21^{\circ} \mathrm{N}$. Cross-section NSCS-WP (red line in Fig. 1a), which is near cross-Sect. $21^{\circ} \mathrm{N}$, was chosen to present the full-depth microstructure measurements (Fig. 2). Because depths in the NSCS and WP are different, by defining layers based on depth, one may bring unfair comparisons by comparing bottom-enhanced turbulence (500-1500 $\mathrm{m}$ in the NSCS) with mild turbulence in the middle layer (500-1500 $\mathrm{m}$ in the WP). Considering that turbulence is usually enhanced at the upper and bottom layers, three layers were defined, including the upper layer (50 $\mathrm{m}$ to the $26-\sigma_{\theta}$ isopycnal $\left.{ }^{23}\right)$, middle layer (the $26-\sigma_{\theta}$ isopycnal to $500 \mathrm{~m}$ above the bottom) and bottom layer (within $500 \mathrm{~m}$ above the bottom ${ }^{3,19}$ ).

Generally, the $\varepsilon$ in the upper layer was higher than that in the other layers, with a maximum value of $1.32 \times 10^{-7}$ $\mathrm{Wkg}^{-1}$ at $\mathrm{C} 09$ (Fig. 2a). Strong fine-scale velocity shear (Fig. 2d) was also observed in the upper layer. Similar $R i_{g}$ patterns (Fig. $2 \mathrm{e}$ ) implied that shear instability played an important role in driving upper layer dissipation. In contrast to $\varepsilon$, the $\kappa$ (Fig. $2 \mathrm{~b}$ ) of all three layers was weakest in the upper layer $\left(10^{-6}-10^{-5} \mathrm{~m}^{2} \mathrm{~s}^{-1}\right)$, where $\kappa$ 
was suppressed by strong stratification (Fig. 2c). The maximum $\kappa$ in the upper layer of the LS (C13) reached $4.55 \times 10^{-5} \mathrm{~m}^{2} \mathrm{~s}^{-1}$, which is of the same order of magnitude as that at the other stations. Our results are different from the fine-scale parameterization results ${ }^{18,19}$ but are similar to the direct measurement results ${ }^{16}$. Turbulence and shear were relatively calm in the middle layer, with $\varepsilon$ being mostly $O\left(10^{-10}\right) \mathrm{Wkg}^{-1}$ and $\varepsilon$ decreasing with depth. However, the $\kappa$ in the middle layer $\left(10^{-5}\right.$ to $\left.10^{-4} \mathrm{~m}^{2} \mathrm{~s}^{-1}\right)$ was generally larger than that in the upper layer and increased with depth due to weakening of stratification below the thermocline ${ }^{24}$.

A notable feature of the cross-section is that the bottom layer turbulence is significantly enhanced over rough topography across the LS (C13), with the maximum $\varepsilon$ and $\kappa$ values reaching $4.29 \times 10^{-8} \mathrm{Wkg}^{-1}$ and $3.7 \times 10^{-2}$ $\mathrm{m}^{2} \mathrm{~s}^{-1}$, respectively, which is comparable to previous work $\mathrm{k}^{25,26}$. The $\varepsilon$ and $\kappa$ on the slope (C37) were also enhanced, with maximum values of $1.74 \times 10^{-8} \mathrm{Wkg}^{-1}$ and $3.5 \times 10^{-2} \mathrm{~m}^{2} \mathrm{~s}^{-1}$, respectively. Turbulence activated over rough topography is considered directly related to high-mode internal tides breaking close to topography and low-mode internal tides breaking over near-critical steep slopes ${ }^{3}$.

Horizontal distributions of turbulence in different layers. The results presented above reveal that turbulence changes dramatically with depth, with $\varepsilon$ ranging from $10^{-10}$ to $10^{-7} \mathrm{Wkg}^{-1}$. Given the above fact, we choose to calculate the layer-averaged dissipation rate $(\langle\varepsilon\rangle)$ and diapycnal diffusivity $(\langle\kappa\rangle)$ to study the horizontal distributions of turbulence (Fig. 3). The averaged dissipation rate in the upper layer $\left(<\varepsilon_{\text {upper }}>\right)$ of the WP was relatively low compared with those in the NSCS, except for the enhanced $<\varepsilon_{\text {upper }}>$ at C09 and C05 (Fig. 3a). Mesoscale eddies and the Kuroshio are major phenomena in this area that may influence the intensified turbulence in the upper layer of the NSCS and WP ${ }^{27,28}$. In the upper layer near the thermocline, except for the geostrophic shear of mesoscale eddies and the Kuroshio, many other mechanisms or physical processes can drive turbulent mixing, such as near-inertial waves, internal tides, and subthermocline eddies ${ }^{29,30}$. However, the $<\varepsilon_{\text {upper }}>$ values of the NSCS and WP were of the same order of magnitude. The pattern of $<\kappa>$ in the upper layer (Fig. 3b) of the NSCS-WP area was similar to that of $<\varepsilon_{\text {upper }}>$ because the distributions of $N^{2}$ in the NSCS above the thermocline were comparable to those in the WP.

The average dissipation rates in the middle layer $\left(<\varepsilon_{\text {middle }}>\right)$ of the NSCS and WP were one order of magnitude lower than those in the upper layer (Fig. 3c). In the WP, the pattern of $\left\langle\varepsilon_{\text {middle }}>\right.$ was similar to that in the upper layer, indicating that the influence of a large mesoscale eddy can reach deep depths to the middle layer, which can be seen in detail in Fig. 2a. The distribution also shows that $<\varepsilon_{\text {middle }}>$ was enhanced at the NSCS slope and LS, but $<\varepsilon_{\text {middle }}>$ in the NSCS basin was as weak as that in the WP, which was close to the background value. Because $N^{2}$ decreases with depth, $<\kappa>$ in the middle layer was not slope-enhanced considering that the slope was shallower than the basin (Fig. 3d).

The averaged dissipation rates in the bottom layer $\left(<\varepsilon_{\text {bottom }}>\right)$ reveal clear horizontal patterns in the NSCS (Fig. 3e). The distribution of $<\varepsilon_{\text {bottom }}>$ shows enhanced turbulence around the NSCS slope and the northern part of the LS, with a maximum $\varepsilon$ at $\mathrm{C} 13$ reaching $10^{-8} \mathrm{Wkg}^{-1}$, which was similar to that in the upper layer. A notable feature is that the $<\varepsilon_{\text {bottom }}>$ in the northern part of the LS (C13) was two orders of magnitude higher than that in the southern part of the LS (C18), which was similar to the background values in the open oceans. This variability reveals that turbulence in the LS was nonuniform. The distribution of $<\varepsilon_{\text {bottom }}>$ in the NSCS was also nonuniform, with a high $<\varepsilon_{\text {bottom }}>$ in the slope area in the northern part and a low $<\varepsilon_{\text {bottom }}>$ in the southern part, which is the NSCS basin. The $<\varepsilon_{\text {bottom }}>$ in the NSCS basin was $O\left(10^{-10}\right) \mathrm{Wkg}^{-1}$. The distribution of averaged $<\kappa>$ in the bottom layer (Fig. 3f) followed the pattern of $<\varepsilon_{\text {bottom }}>$ and was influenced by depth-correlated $N^{2}$.

Comparison of the turbulence activities of the NSCS and WP. To clarify the difference between the turbulence activities of the NSCS and WP, we first present the zonal distributions of $<\varepsilon>$ (Fig. 4a) and $\langle\kappa\rangle$ (Fig. 4 b) in the NSCS and WP. In the zonal direction, the variations in $\left\langle\varepsilon_{\text {upper }}>\right.$ and $<\varepsilon_{\text {middle }}>$ have similar trends, with values of $10^{-8}$ to $10^{-9} \mathrm{Wkg}^{-1}$ and $10^{-9}$ to $10^{-10} \mathrm{Wkg}^{-1}$, respectively. A slight increase was observed near $122^{\circ} \mathrm{E}$, which was considered the effect of eddy-induced turbulence. $<\varepsilon_{\text {bottom }}>$ shows a different pattern from $<\varepsilon_{\text {upper }}>$, with significant increases at the LS $\left(122.5^{\circ} \mathrm{E}\right)$ and $118.25^{\circ} \mathrm{E}$, indicating the effects of topography. The zonal distribution of $\langle\kappa\rangle$ was similar to that of $\langle\varepsilon\rangle .\langle\kappa\rangle$ was not as high as that reported by previous indirect measurements ${ }^{18,19}$, which may be induced by uncertainties of the fine-scale method near rough topography ${ }^{31}$.

The average dissipation rates and diapycnal diffusivity of different layers are shown in Fig. 4c,d to evaluate the differences between the WP $\left(<\varepsilon_{\mathrm{WP}}>\right.$ and $\left.<\kappa_{\mathrm{WP}}>\right)$, LS $\left(<\varepsilon_{\mathrm{LS}}>\right.$ and $\left.<\kappa_{\mathrm{LS}}>\right)$, NSCS basin $\left(<\varepsilon_{\mathrm{NSCSbasin}}>\right.$ and $<$ $\left.\kappa_{\mathrm{NSCSbasin}}>\right)$ and NSCS $\left(<\varepsilon_{\mathrm{NSCS}}>\right.$ and $\left.<\kappa_{\mathrm{NSCS}}>\right)$ considering the horizontal pattern shown in Fig. 3. Subscripts LS, WP and NSCS correspond to stations in the same color in Fig. 1. The NSCS subscript represents both the NSCS slope and NSCS basin in Fig. 1. Turbulence was more energetic in the LS than in the NSCS and WP at all layers, as shown in previous work ${ }^{19}$. The ratios of $\left\langle\varepsilon_{\mathrm{NSCS}}>\right.$ to $\left\langle\varepsilon_{\mathrm{WP}}>\right.$ in the upper, middle and bottom layers were $0.94,0.81$ and 14.89 , respectively, indicating that the dissipation rates were at the same level in the upper and middle layers, while in the bottom layer, $\left\langle\varepsilon_{\mathrm{NSCS}}>\right.$ was one order of magnitude larger than $\left\langle\varepsilon_{\mathrm{WP}}\right\rangle$. The ratios of $\left\langle\kappa_{\mathrm{NSCS}}>\right.$ to $<\kappa_{\mathrm{WP}}>$ in the upper, middle and bottom layers were $0.62,0.99$, and 3.38 , respectively, showing that the diffusivities in the NSCS were smaller than or equal to those in the WP in the upper and middle layers. Enhanced diffusivities were observed in the bottom layer of the NSCS and were larger than those in the WP by a factor of 3 instead of by 2 orders of magnitude ${ }^{18}$. The ratios of $\left\langle\varepsilon_{\text {NSCSbasin }}>\right.$ to $<\varepsilon_{W P}>$ in the upper, middle and bottom layers were $0.96,0.57$ and 2.06, respectively, revealing the same level of $\varepsilon$ in the NSCS basin and WP. The ratios of $\left\langle\kappa_{\mathrm{NSCSbasin}}>\right.$ to $<\kappa_{\mathrm{WP}}>$ in the upper, middle and bottom layers were $0.40,0.90$, and 1.08 , respectively. Surprisingly, both the dissipation rates and diffusivities of all three layers of the NSCS basin and WP were similar.

Considering the influence of the definition of different layers, we also calculated the average $\varepsilon$ and $\kappa$ at different layers based on depth (see Supplementary Figs. S1 and S2 online). The distributions of $\varepsilon$ at the upper (50-500 m) 
a

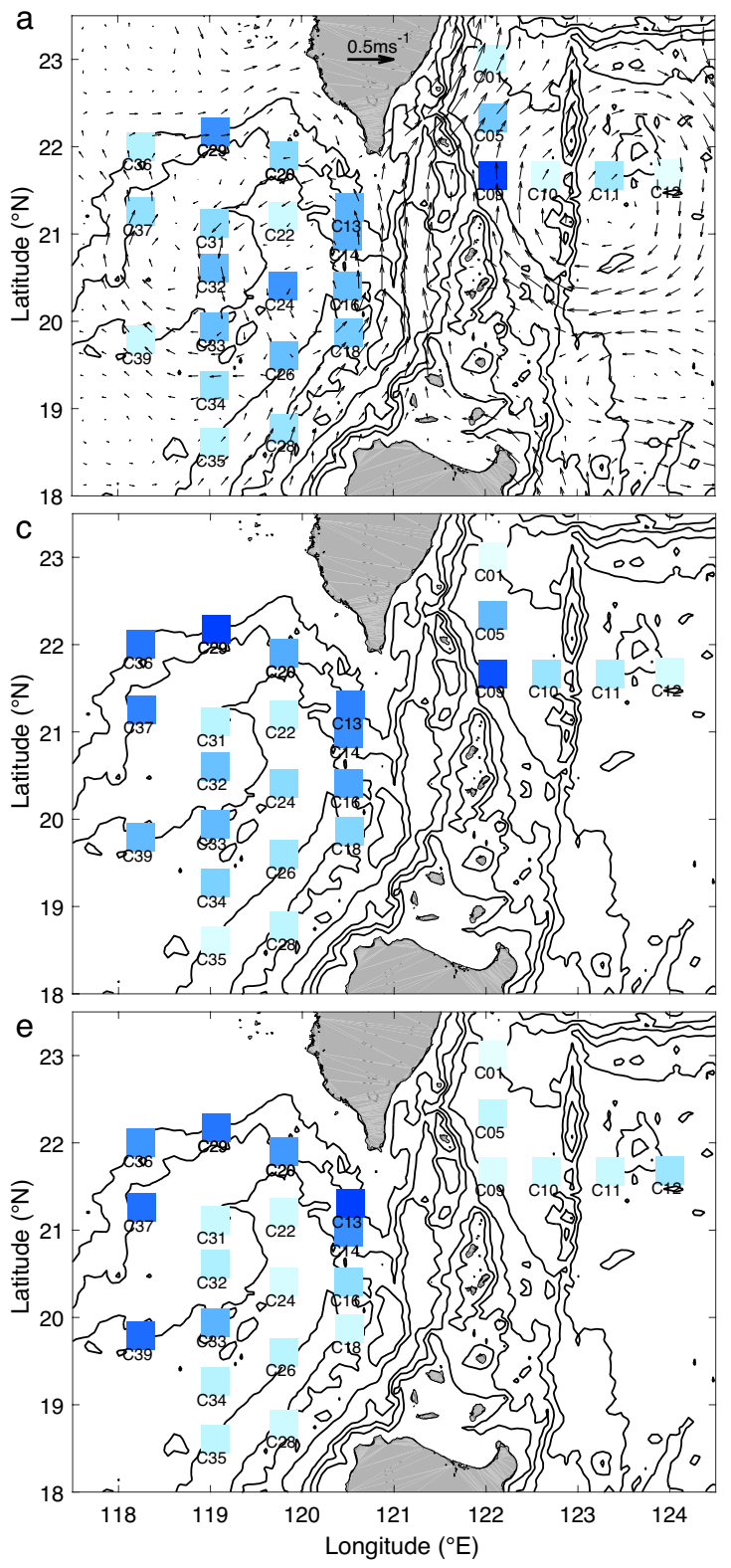

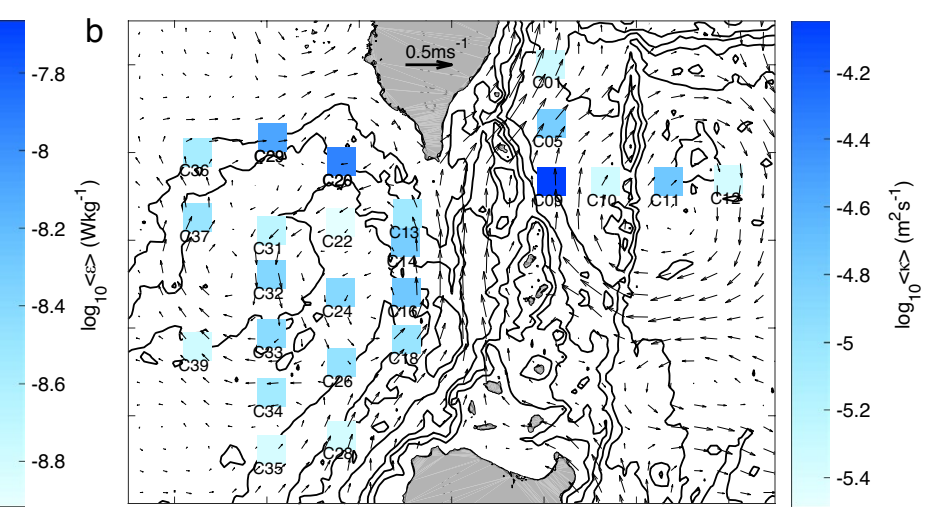
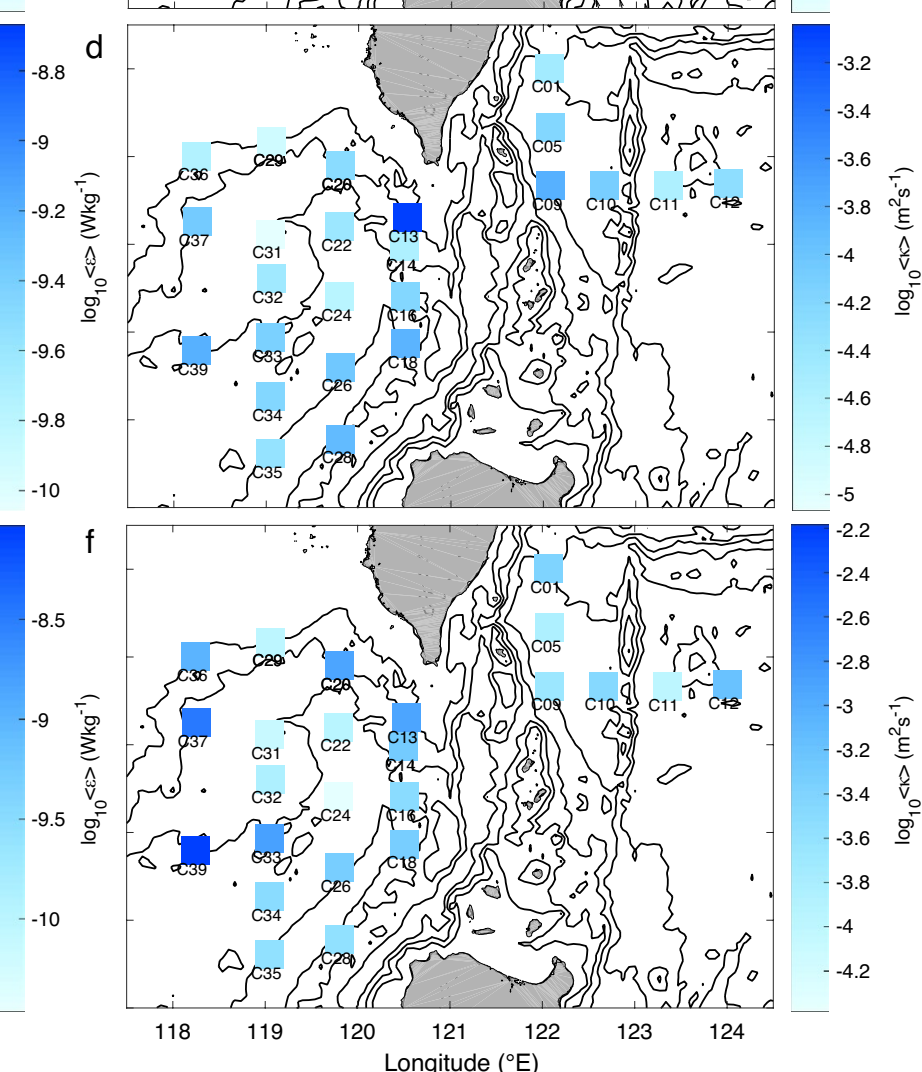

Figure 3. Maps of the layer-averaged dissipation rate $(<\varepsilon>$, left) and diapycnal diffusivity ( $<\kappa>$, right) for the upper layer $(\mathbf{a}, \mathbf{b})$, middle layer $(\mathbf{c}, \mathbf{d})$, and bottom layer $(\mathbf{e}, \mathbf{f})$. Mean surface geostrophic currents from May 29 to June 24, 2018, are shown in (a) and (b). Figures were plotted using MATLAB R2016b (http://www.mathworks. $\mathrm{com} /)$.

and bottom layers (within $500 \mathrm{MAB}$ ), defined based on depth, are similar to those in Figs. 3 and 4. A dramatic difference in $\kappa$ is shown in the middle layer $(500-1500 \mathrm{~m})$ because the depth in the NSCS is shallower than that in the WP. This results in a comparison of bottom-enhanced turbulence in the NSCS with mild turbulence in the middle layer of the WP, and this comparison is unfair.

\section{Discussion}

Temporal variation in dissipation rates. Given that the occurrence of turbulence activity is intermittent and typically has strong temporal variations due to different forcing mechanism $s^{30}$, it is quite challenging to give a robust horizontal distribution of turbulent mixing based on one instantaneous observation or observations at different times. Compared to instantaneous microstructure measurements, the moored ADCP is more effective in continuously observing oceanic fine-scale velocity profiles at a fixed location and hence estimating fine-scale turbulent shear and its resultant mixing ${ }^{32,33}$. To clarify the confidence of our study, the GHP method was applied to ADCP data to estimate the time series of $\varepsilon$ and to evaluate the variation in $\varepsilon$.

The results shown in Fig. 5a,b are examples of the bottom $\varepsilon$ time series from July 31 to September 4, 2017, and the synchronous barotropic tidal current derived from the TPXO 7.2 inverse model (http://volkov.oce.orst.edu/ tides/global.html). Dissipation rates show significant variations but are not highly correlated with tidal currents. 

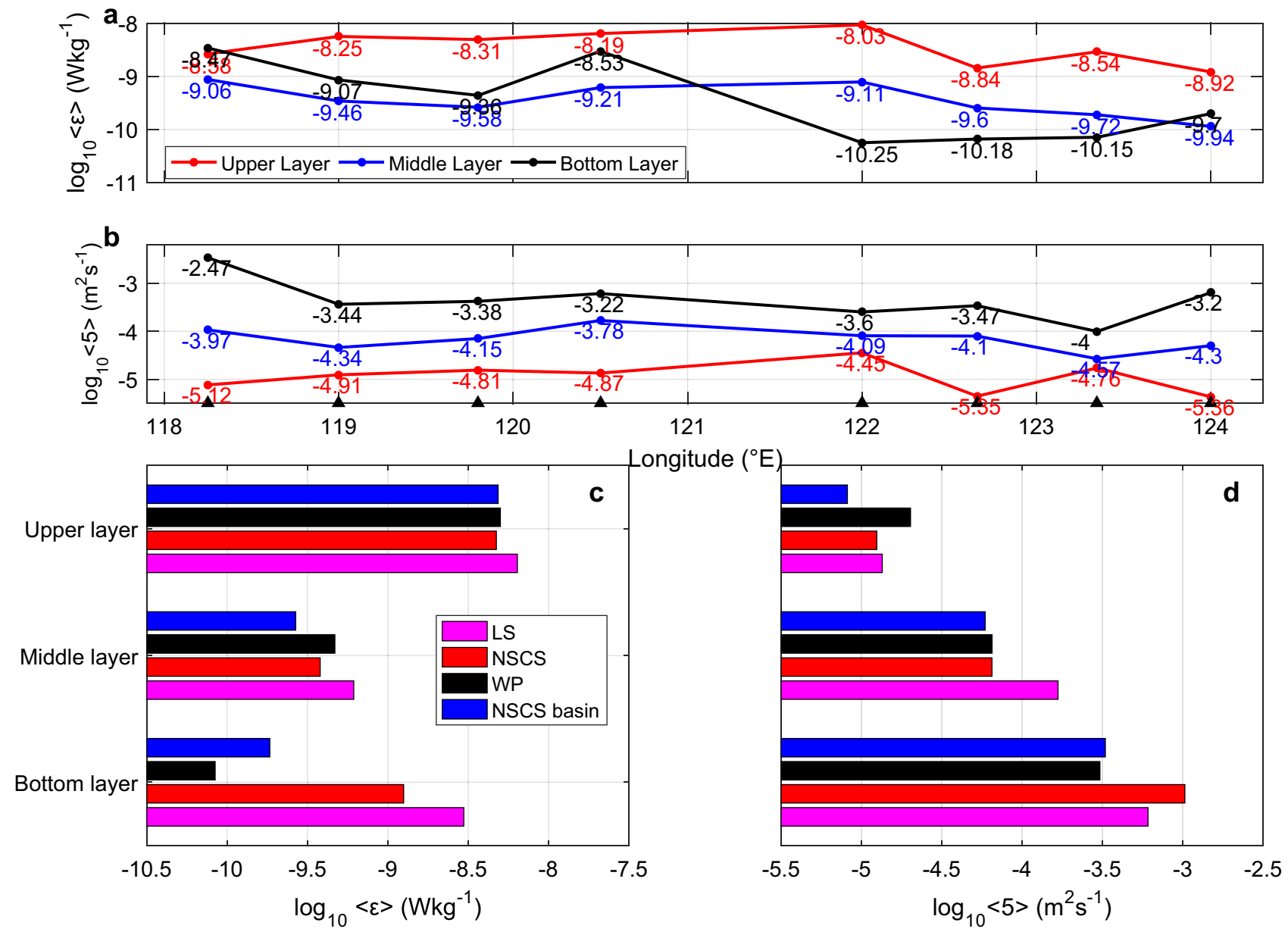

Figure 4. Zonal distribution of $\langle\varepsilon\rangle$ and $\langle\kappa\rangle(\mathbf{a}, \mathbf{b})$ and comparison of averaged dissipation rates and diapycnal diffusivities for different areas (c,d) in each layer. The average values of the LS, WP and NSCS basin are calculated based on stations in the same color in Fig. 1. The NSCS includes stations of the NSCS slope and NSCS basin in Fig. 1.

The mean value $\left(\log _{10} \mu_{\varepsilon}\right)$ and standard deviation $\left(\log _{10} \sigma_{\varepsilon}\right)$ of the normal distribution of dissipation rates are $-8.35 \mathrm{Wkg}^{-1}$ and $0.52 \mathrm{Wkg}^{-1}$, respectively (Fig. $5 \mathrm{c}$ ). The mean value is very close to the directly observed bottom dissipation rate at $\mathrm{C} 29$ in $\log 10$ space, which is $-8.42 \mathrm{Wkg}^{-1}$. The standard deviation also indicates that most values could distribute within one order of magnitude of the mean value. The standard deviation can support the study of dissipation rate distribution with orders of magnitude variation.

We also took repeated VMP-X casts in different years at C29 and C20. Repeat casts at C20 were taken on June 06,2018 , and July 27, 2019. The results showed that the values and vertical structures of $\varepsilon$ (Fig. $5 \mathrm{~d}$ ) are similar. Both profiles present enhanced $\varepsilon$ in the upper and bottom layers and low $\varepsilon$ in the middle layer. Repeat casts at C29 (Fig. 5e) were taken on December 10, 2017, and July 21, 2019. The depth changed $107 \mathrm{~m}$ between the two deployments because of complicated bathymetry near the LS, although the two casts were very close to each other. The structures of the two profiles were also similar to each other, with bottom-enhanced dissipation rates and $\varepsilon$ values on the same order of magnitude. Thus, both the time series of bottom $\varepsilon$ from the fine-scale method and the repeat microstructure measurements indicate that the distribution of turbulence activities based on our direct measurements is credible.

Effect of topography on the dissipation rate distribution. Turbulence in the SCS is revealed to be remarkably enhanced, mainly due to internal tides, which are generated from the LS and propagate westward into the $\mathrm{SCS}^{9,34}$. High-mode internal tides dissipate locally in the near-field, and low-mode internal tides propagate to the far-field ${ }^{35}$. As internal waves propagate, variable bathymetry plays an important role in the transfer of low-mode energy to smaller scales, at which dissipation occurs ${ }^{36}$. Since dissipation rates were enhanced mainly in the bottom layer, we present the relationship between $\left\langle\varepsilon_{\text {bottom }}>\right.$ and topography parameters such as topography roughness $\left(\delta^{2}\right.$, Fig. 6a) and slope criticality for semidiurnal tides $(\gamma$, Fig. 6b). This enhancement, however, does not occur throughout the entire NSCS but mainly in sloped and rough areas. The topography of the NSCS basin is relatively smooth, with a low $<\varepsilon>$ of $O\left(10^{-10}\right) \mathrm{Wkg}^{-1}$. A high $<\varepsilon>$ of $O\left(10^{-8}\right) \mathrm{Wkg}^{-1}$ was combined with rough topography at the NSCS slope and LS. The high roughness corresponded to high-mode internal tides dissipating locally ${ }^{22}$. Several stations in the WP and LS with higher roughness showed low dissipation rates because 
a
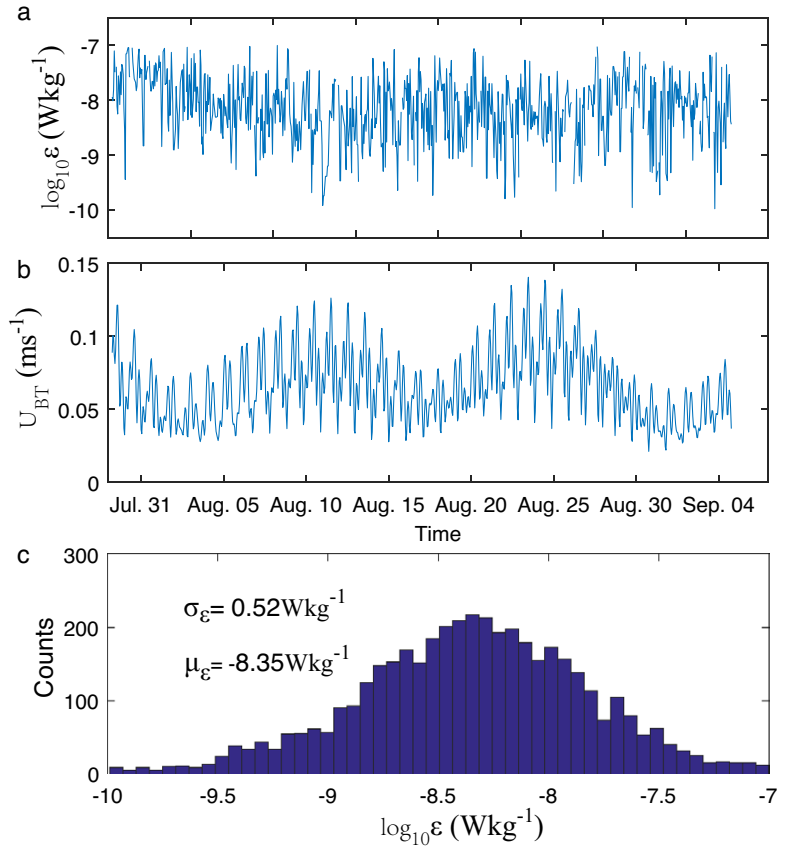

d

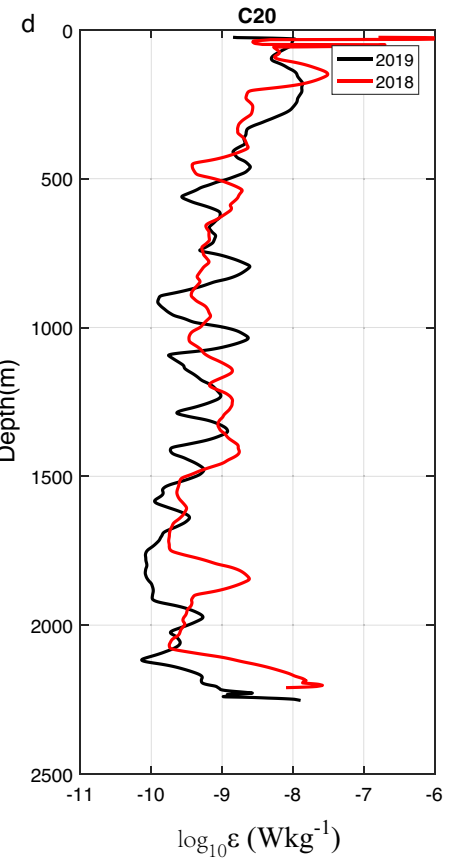

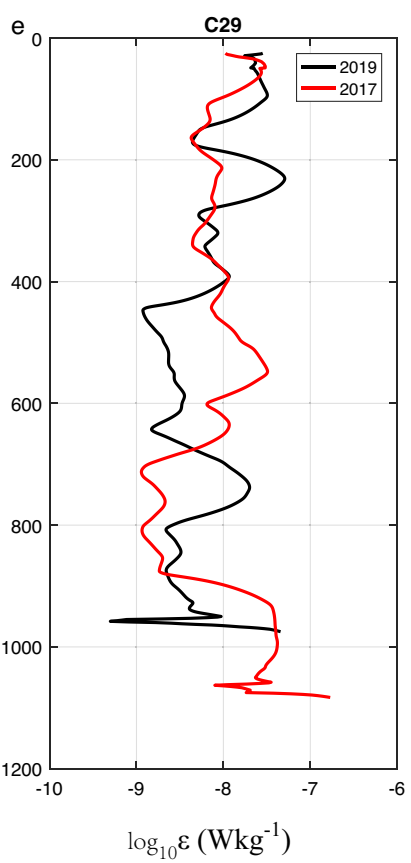

Figure 5. Panels (a,b) are the time series of the dissipation rates and the synchronous barotropic tidal current. Panel (c) shows the histogram of the fine-scale dissipation rate during the moored ADCP observation period. $\mu_{\varepsilon}$ and $\sigma_{\varepsilon}$ are the mean value and standard deviation of the normal distribution of dissipation rates in $\log 10$ space. Panels (c,d) are repeated microstructure observations at C20 and C29 in different years.
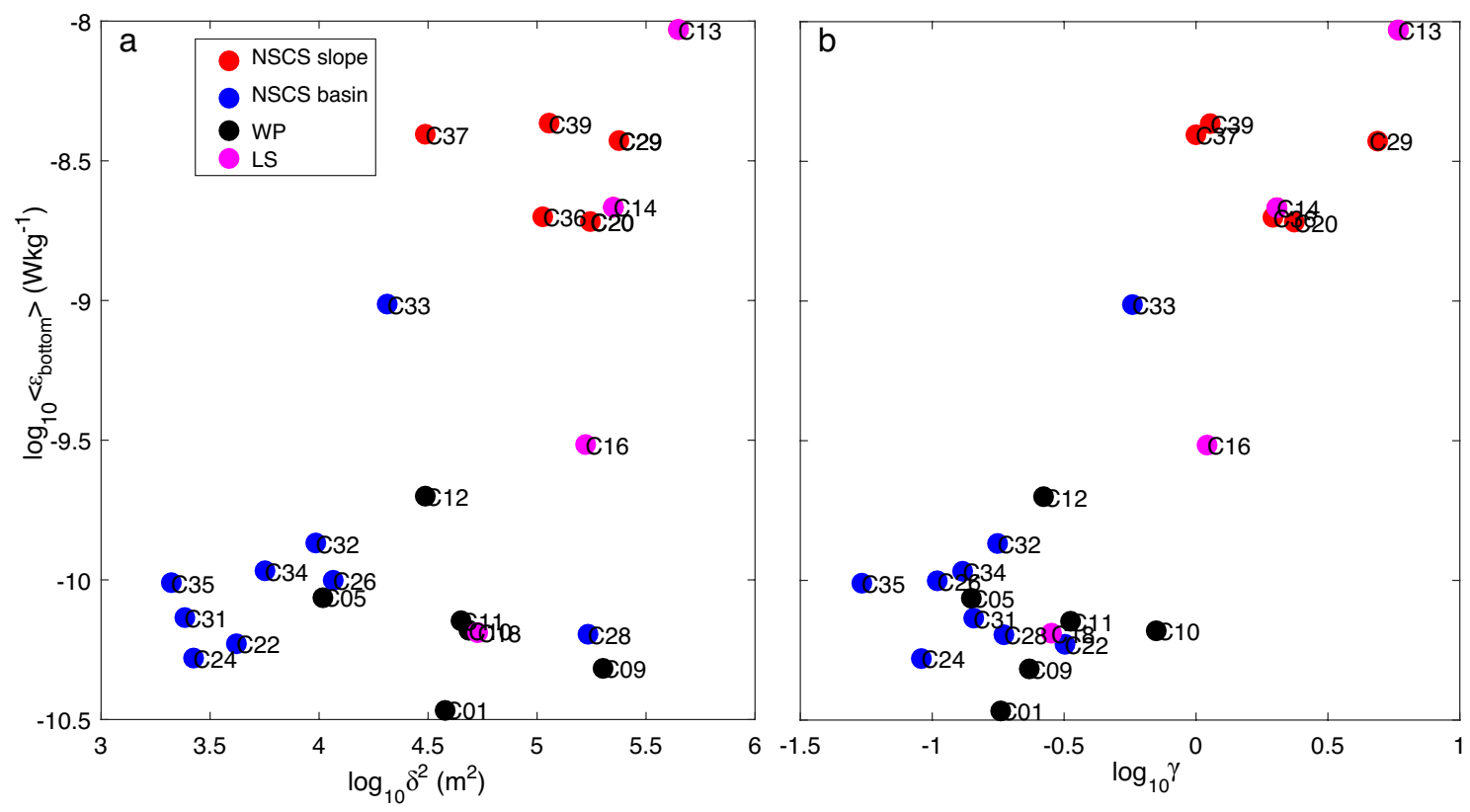

Figure 6. Average dissipation rate at the bottom layer $\left(<\varepsilon_{\text {bottom }}>\right)$ plotted against topography roughness $\left(\delta^{2}\right)$ and slope criticality $(\gamma)$ for semidiurnal tides. These symbols correspond to the station symbols in Fig. 1.

most internal tide energy is not dissipated near topographic sources and instead radiates away as low-mode internal waves ${ }^{3}$. In the NSCS basin, internal tides propagated in a low mode with less interaction with smooth topography, showing low dissipation ${ }^{9}$. The interaction between low-mode internal waves and rough topography is strongly dependent on the steepness of the topography ${ }^{37}$. When internal tides shoal onto the continental slope, near-critical topography $(\gamma \sim 1)$ scatters low-mode internal tides to smaller wavelengths, leading to intensified dissipation near the slope ${ }^{38,39}$. Thus, $<\varepsilon_{\text {bottom }}>$ (Fig. 6 b) was highly related to slope criticality for semidiurnal tides, showing high dissipation near the slope and low dissipation in the basin. 
We present a clear picture of the three-dimensional distribution of turbulence based on full-depth microstructure data taken at the NSCS and WP. Our analyses show that in the upper and middle layers, turbulence activities in the NSCS and WP were of the same order of magnitude, with $<\varepsilon>$ ranging from $10^{-8}$ to $10^{-9} \mathrm{Wkg}^{-1}$ and $\left\langle\kappa>\right.$ ranging from $10^{-5}$ to $10^{-6} \mathrm{~m}^{2} \mathrm{~s}^{-1}$. Enhanced turbulence was observed only near rough topography and steep slopes in the bottom layer, with the average dissipation rates of the NSCS being one order of magnitude larger than those of the WP. However, the enhanced diffusivities in the bottom layer of the NSCS were larger than those in the bottom layer of the WP by a factor of 3 instead of by 2 orders of magnitude. This enhancement, however, does not occur throughout the entire NSCS but mainly at the slope and little in the basin. The distribution of turbulence in the bottom layer was mainly induced by the breaking of internal tides at the slope and propagation in the basin. To our knowledge, this study was the first to compare the turbulence activities of the NSCS and WP based on direct full-depth microstructure observations. These results may appear surprising in light of previous studies but are in fact consistent with predictions from internal wave-topography interaction theory. Since the topography near LS covers a wide range of bathymetric features, we speculate that the relationship between direct observed dissipation and topography may be applied to the global ocean.

\section{Methods}

Microstructure estimates of turbulent dissipation. The microstructure data were analyzed by following previous work by Wolk et al. $(2002)^{40}$. The dissipation rate was estimated by fitting the Nasmyth spectrum to the measured shear spectra over consecutive half-overlapping 10-m depth segments; thus, the vertical resolution of $\varepsilon$ was $5 \mathrm{~m}$. The same spacing was adopted for profiles of the potential temperature and shear. Diapycnal diffusivity $(\kappa)$ was estimated by following the Osborn $(1980)^{41}$ formula $\kappa=\Gamma \varepsilon / N^{2}$, where $\Gamma$ is the mixing efficiency, and $\Gamma=0.2$ is typically adopted. Mixing efficiency may vary significantly in the abyssal ocean ${ }^{42,43}$, while there is no widely accepted value of $\Gamma$ and method besides $\Gamma=0.2$. We choose $\Gamma=0.2$ in this study because this study focuses on the distribution of the dissipation rate rather than diapycnal diffusivity, which is highly dependent on depth. Buoyancy frequency was calculated as $N=\sqrt{-\frac{g}{\rho_{0}} \frac{d \rho}{d z}}$. The estimated $\varepsilon$ and $\kappa$ values in the top $10 \mathrm{~m}$ were removed due to contamination by the ship. Velocity shear $S=\sqrt{(\partial u / \partial z)^{2}+(\partial v / \partial z)^{2}}$, where $u$ and $v$ represent the zonal and meridional components from the LADCP, respectively. $N^{2}$ and $S^{2}$ were interpolated to a $10-\mathrm{m}$ vertical spacing, corresponding to the resolution of $\varepsilon$. The gradient Richardson number, $R i_{g}=\frac{\partial \rho}{\partial z} \frac{g}{\rho_{o}}\left(\frac{\partial \bar{u}}{\partial z}\right)^{-2}$, is the ratio of the stabilizing forces of density stratification to the destabilizing influences of velocity shear.

GHP parameterization. GHP parameterization ${ }^{44}$ depends on the fine-scale shear $\left\langle v_{z}^{2}\right\rangle$ and strain variance $\left\langle\xi_{z}^{2}\right\rangle$ as.

$$
\begin{gathered}
\varepsilon_{\mathrm{GHP}}=\varepsilon_{0}\left(\frac{N^{2}}{N_{0}^{2}}\right) \frac{\left\langle v_{z}^{2}\right\rangle^{2}}{G M\left\langle v_{z}^{2}\right\rangle^{2}} h\left(R_{w}\right) j\left(\frac{f}{\bar{N}}\right) \\
h\left(R_{w}\right)=\frac{3}{2 \sqrt{2}} \frac{R_{w}+1}{R_{w} \sqrt{R_{w}-1}} \\
j\left(\frac{f}{\bar{N}}\right)=\frac{f \arccos h(N / f)}{f_{30} \arccos h\left(N_{0} / f_{30}\right)} \\
R_{w}=\left\langle v_{z}^{2}\right\rangle / \bar{N}^{2}\left\langle\xi_{z}^{2}\right\rangle
\end{gathered}
$$

where $\varepsilon_{0}=8 \times 10^{-10} \mathrm{Wkg}^{-1}$ is a background constant value; $N$ is the buoyancy frequency, with $N_{0}=5.42 \times 10^{-3}$ $\mathrm{rads}^{-1} ; f$ is the Coriolis frequency, with $f_{30}=f\left(30^{\circ}\right) ;\left\langle v_{z}^{2}\right\rangle$ is the shear variance; $G M\left\langle v_{z}^{2}\right\rangle$ is the shear variance from the GM model spectrum; and $R_{\mathrm{w}}$ is the ratio of the buoyancy-frequency-normalized shear variance to strain variance. Here, $R_{\mathrm{w}}$ is set to $7^{45}$. The strain variance $\left\langle\xi_{z}^{2}\right\rangle$ is estimated from the buoyancy frequency, $\left\langle\xi_{z}^{2}\right\rangle=\left\langle\left(N^{2}-\bar{N}^{2}\right)^{2} / \bar{N}^{4}\right\rangle$.

To compute the buoyancy-frequency-normalized shear variance, $\left\langle v_{z}^{2}\right\rangle / \bar{N}^{2}$, the shear profiles were first obtained from the hourly $75 \mathrm{kHz}$ ADCP velocity data with $8 \mathrm{~m}$ depth resolution and the buoyancy frequency profiler from the global physical analysis and a coupled forecasting product ${ }^{46}$ modeled by the Met Office Coupled Atmosphere-Land-Ocean-Ice data assimilation system (CPLDA). The vertical shear spectrum of the velocity in the segment from 848 to $1196 \mathrm{~m}$ was calculated. Then, the buoyancy frequency-normalized shear variance, $\left\langle v_{z}^{2}\right\rangle / N^{2}$, was obtained by integrating the shear spectrum from the minimum wavenumber $k_{\min }=2 \pi / 180 \mathrm{~m}$ to $k_{\max }=2 \pi / 60 \mathrm{~m}^{47,48} \cdot G M\left\langle v_{z}^{2}\right\rangle$ was also obtained within the same integral interval.

$$
\frac{\left\langle v_{z}^{2}\right\rangle}{\bar{N}^{2}}=\int_{k_{\min }}^{k_{\max }} S\left[\frac{v_{z}}{\bar{N}}\right]\left(k_{z}\right) d k_{z}
$$

Characteristics of topography. Bathymetry data from the General Bathymetric Chart of the Oceans 2014 were used to evaluate topography roughness $\delta^{2}$ (Fig. 1b) and slope criticality $\gamma$ for semidiurnal tides (Fig. 1c). Topography roughness is defined as the variance calculated in a $0.2^{\circ} \times 0.2^{\circ}$ area, a reasonable scale for 
internal tide generation ${ }^{49}$. Slope criticality is defined as $\gamma=(d h / d x) / s$, where $d h / d x$ is the topographic gradient and $s=\sqrt{\left(f^{2}-\omega^{2}\right)-\left(N^{2}-\omega^{2}\right)}$ is the internal tide characteristic steepness, where $\omega$ is the internal wave frequency and $f$ is the Coriolis parameter ${ }^{39}$. The climatological temperature and salinity data in the 2013 World Ocean Atlas were used to calculate the $N^{2}$ used in $\gamma$ (Fig. 1c).

\section{Data availability}

Bathymetry data from the General Bathymetric Chart of the Oceans 2014 can be downloaded from the website https://www.gebco.net/data_and_products/historical_data_sets/\#gebco_2014. The climatological temperature and salinity data in the 2013 World Ocean Atlas are obtained from https://www.nodc.noaa.gov/OC5/woa13/ woa13data.html. The geostrophic currents are obtained from http://marine.copernicus.eu/. Direct measurements of microstructure data, squared buoyancy frequency and shear variance are available from the corresponding author upon request. The buoyancy frequency data are calculated from the global physical analysis and a coupled forecasting product by the Met Office Coupled Atmosphere-Land-Ocean-Ice data assimilation system, which can be obtained from https://resources.marine.copernicus.eu/?option=com_csw\&view=details\&product_id= GLOBAL_ANALYSISFORECAST_PHY_CPL_001_015.

Received: 7 April 2021; Accepted: 6 July 2021

Published online: 21 July 2021

\section{References}

1. Liang, C.-R., Shang, X.-D., Qi, Y.-F., Chen, G.-Y. \& Yu, L.-H. Enhanced diapycnal mixing between water masses in the western equatorial pacific. J. Geophys. Res. Oceans 124, 8102-8115 (2019).

2. McCreary, J. P. \& Lighthill, J. A linear stratified ocean model of the equatorial undercurrent. Philos. Trans. R. Soc. Lond. Ser. A Math. Phys. Sci. 298, 603-635 (1981).

3. MacKinnon, J. A. et al. Climate process team on internal wave-driven ocean mixing. Bull. Am. Meteor. Soc. 98, 2429-2454 (2017).

4. Whalen, C. B. et al. Internal wave-driven mixing: Governing processes and consequences for climate. Nat. Rev. Earth Environ. 1, 606-621 (2020).

5. Munk, W. \& Wunsch, C. Abyssal recipes II: Energetics of tidal and wind mixing. Deep Sea Res. Part I 45, 1977-2010 (1998).

6. Lueck, R. G. \& Mudge, T. D. Topographically induced mixing around a shallow seamount. Science 276, 1831 (1997).

7. Kunze, E. \& Toole, J. M. Tidally driven vorticity, diurnal shear, and turbulence atop fieberling seamount. J. Phys. Oceanogr. 27, 2663-2693 (1997).

8. Carter, G. S. \& Gregg, M. C. Intense, variable mixing near the head of monterey submarine canyon. J. Phys. Oceanogr. 32, 3145-3165 (2002).

9. Alford, M. H. et al. The formation and fate of internal waves in the South China Sea. Nature 521, 65-69 (2015).

10. Klymak, J. M. et al. The breaking and scattering of the internal tide on a continental slope. J. Phys. Oceanogr. 41, 926-945 (2011).

11. Alford, M. H. et al. Energy flux and dissipation in Luzon strait: Two tales of two ridges. J. Phys. Oceanogr. 41, 2211-2222 (2011).

12. Quan, Q. \& Xue, H. Influence of abyssal mixing on the multilayer circulation in the south China sea. J. Phys. Oceanogr. 49, 3045-3060 (2019).

13. Liu, Z. \& Lozovatsky, I. Upper pycnocline turbulence in the northern South China Sea. Chin. Sci. Bull. 57, 2302-2306 (2012).

14. Lozovatsky, I., Liu, Z., Fernando, H. J. S., Hu, J. \& Wei, H. The TKE dissipation rate in the northern South China Sea. Ocean Dyn. 63, 1189-1201 (2013).

15. Yang, Q., Tian, J., Zhao, W., Liang, X. \& Zhou, L. Observations of turbulence on the shelf and slope of northern South China Sea. Deep Sea Res. Part I 87, 43-52 (2014).

16. Shang, X. D., Liang, C. R. \& Chen, G. Y. Spatial distribution of turbulent mixing in the upper ocean of the South China Sea. Ocean Sci. 13, 503-519 (2017).

17. Liang, C.-R., Chen, G.-Y. \& Shang, X.-D. Observations of the turbulent kinetic energy dissipation rate in the upper central South China Sea. Ocean Dyn. 67, 597-609 (2017).

18. Tian, J., Yang, Q. \& Zhao, W. Enhanced diapycnal mixing in the south China Sea. J. Phys. Oceanogr. 39, 3191-3203 (2009).

19. Yang, Q., Zhao, W., Liang, X. \& Tian, J. Three-dimensional distribution of turbulent mixing in the south china Sea*. J. Phys. Oceanogr. 46, 769-788 (2016).

20. Buijsman, M. C., Legg, S. \& Klymak, J. Double-ridge internal tide interference and its effect on dissipation in luzon strait. J. Phys. Oceanogr. 42, 1337-1356 (2012).

21. Jayne, S. R. The impact of abyssal mixing parameterizations in an ocean general circulation model. J. Phys. Oceanogr. 39, 1756-1775 (2009).

22. Melet, A., Hallberg, R., Legg, S. \& Polzin, K. Sensitivity of the ocean state to the vertical distribution of internal-tide-driven mixing. J. Phys. Oceanogr. 43, 602-615 (2013).

23. Nan, F. et al. Isopycnal mixing of interhemispheric intermediate waters by subthermocline eddies east of the Philippines. Sci. Rep. 9, 2957 (2019).

24. Liu, Z. et al. Weak thermocline mixing in the north pacific low-latitude western boundary current system. Geophys. Res. Lett. 44, 10530-510539 (2017).

25. Polzin, K. L., Toole, J. M., Ledwell, J. R. \& Schmitt, R. W. Spatial variability of turbulent mixing in the abyssal ocean. Science 276, 93 (1997).

26. Waterhouse, A. F. et al. Global patterns of diapycnal mixing from measurements of the turbulent dissipation rate. J. Phys. Oceanogr. 44, 1854-1872 (2014).

27. Jing, Z. et al. Turbulent diapycnal mixing in the subtropical northwestern Pacific: Spatial-seasonal variations and role of eddies. J. Geophys. Res. Oceans 116, C10028 (2011).

28. Chen, Z. et al. Enhanced turbulent mixing by an anticyclonic eddy observed in the subtropical Northwestern Pacific Ocean. Region. Stud. Marine Sci. 45, 101830 (2021).

29. Zhang, Z. et al. Elevated diapycnal mixing by a subthermocline eddy in the western equatorial pacific. Geophys. Res. Lett. 46, 2628-2636 (2019).

30. Zhang, Z., Qiu, B., Tian, J., Zhao, W. \& Huang, X. Latitude-dependent finescale turbulent shear generations in the Pacific tropicalextratropical upper ocean. Nat. Commun. 9, 4086 (2018).

31. Liang, C.-R., Shang, X.-D., Qi, Y.-F., Chen, G.-Y. \& Yu, L.-H. Assessment of fine-scale parameterizations at low latitudes of the North Pacific. Sci. Rep. 8, 10281 (2018).

32. Alford, M. H., MacKinnon, J. A., Pinkel, R. \& Klymak, J. M. Space-time scales of shear in the north pacific. J. Phys. Oceanogr. 47, 2455-2478 (2017). 
33. Guan, S., Zhao, W., Huthnance, J., Tian, J. \& Wang, J. Observed upper ocean response to typhoon Megi (2010) in the Northern South China Sea. J. Geophys. Res. Oceans 119, 3134-3157 (2014).

34. Cao, A. et al. Upper ocean shear in the northern South China Sea. J. Oceanogr. 75, 525-539 (2019).

35. Niwa, Y. \& Hibiya, T. Three-dimensional numerical simulation of M2 internal tides in the East China Sea. J. Geophys. Res. Oceans 109, 2 (2004).

36. Vic, C. et al. Deep-ocean mixing driven by small-scale internal tides. Nat. Commun. 10, 2099 (2019).

37. Legg, S. Scattering of low-mode internal waves at finite isolated topography. J. Phys. Oceanogr. 44, 359-383 (2014).

38. Jalali, M. \& Sarkar, S. Large eddy simulation of flow and turbulence at the steep topography of luzon strait. Geophys. Res. Lett. 44, 9440-9448 (2017).

39. Xie, X. et al. Deep sea currents driven by breaking internal tides on the continental slope. Geophys. Res. Lett. 45, 6160-6166 (2018).

40. Wolk, F., Yamazaki, H., Seuront, L. \& Lueck, R. G. A new free-fall profiler for measuring biophysical microstructure. J. Atmos. Ocean. Tech. 19, 780-793 (2002).

41. Osborn, T. R. Estimates of the local rate of vertical diffusion from dissipation measurements. J. Phys. Oceanogr. 10, 83-89 (1980).

42. Mashayek, A. et al. Efficiency of turbulent mixing in the abyssal ocean circulation. Geophys. Res. Lett. 44, 6296-6306 (2017).

43. Ijichi, T. \& Hibiya, T. Observed variations in turbulent mixing efficiency in the deep ocean. J. Phys. Oceanogr. 48, 1815-1830 (2018).

44. Gregg, M. C., Sanford, T. B. \& Winkel, D. P. Reduced mixing from the breaking of internal waves in equatorial waters. Nature 422, 513-515 (2003).

45. Kunze, E., Firing, E., Hummon, J. M., Chereskin, T. K. \& Thurnherr, A. M. Global abyssal mixing inferred from lowered ADCP shear and CTD strain profiles. J. Phys. Oceanogr. 36, 1553-1576 (2006).

46. Lea, D. J. et al. Assessing a new coupled data assimilation system based on the met office coupled atmosphere-land-ocean-sea ice model. Mon. Weather Rev. 143, 4678-4694 (2015).

47. Sheen, K. L. et al. Rates and mechanisms of turbulent dissipation and mixing in the Southern Ocean: Results from the diapycnal and isopycnal mixing experiment in the southern ocean (DIMES). J. Geophys. Res. Oceans 118, 2774-2792 (2013).

48. Sheen, K. L. et al. Modification of turbulent dissipation rates by a deep Southern Ocean eddy. Geophys. Res. Lett. 42, 3450-3457 (2015).

49. St Laurent, L. \& Garrett, C. The role of internal tides in mixing the deep ocean. J. Phys. Oceanogr. 32, 2882-2899 (2002).

\section{Acknowledgements}

We thank Changrong Liang for providing suggestions during the revision process of dissipation. This work was jointly supported by the National Key Research and Development Program of China (2017YFC1403401) and the National Natural Science Foundation of China (41706012).

\section{Author contributions}

J.W., F.Y. and F.N. conceived the research. J.W., F.N., Q.R., and Z.C. collected hydrographic and microstructure data. J.W. and Z.C. processed the microstructure data. Z.C. and T.Z. processed the geostrophic current data. J.W. conducted most of the data analysis and wrote the first draft of the paper with all the authors' contributions to the revisions. All authors reviewed the manuscript.

\section{Competing interests}

The authors declare no competing interests.

\section{Additional information}

Supplementary Information The online version contains supplementary material available at https://doi.org/ 10.1038/s41598-021-94223-3.

Correspondence and requests for materials should be addressed to F.Y.

Reprints and permissions information is available at www.nature.com/reprints.

Publisher's note Springer Nature remains neutral with regard to jurisdictional claims in published maps and institutional affiliations.

(c) (1) Open Access This article is licensed under a Creative Commons Attribution 4.0 International License, which permits use, sharing, adaptation, distribution and reproduction in any medium or format, as long as you give appropriate credit to the original author(s) and the source, provide a link to the Creative Commons licence, and indicate if changes were made. The images or other third party material in this article are included in the article's Creative Commons licence, unless indicated otherwise in a credit line to the material. If material is not included in the article's Creative Commons licence and your intended use is not permitted by statutory regulation or exceeds the permitted use, you will need to obtain permission directly from the copyright holder. To view a copy of this licence, visit http://creativecommons.org/licenses/by/4.0/.

(C) The Author(s) 2021 